\title{
Examination of behavior of lysine on methane (95\%)-propane (5\%) hydrate formation by the use of different impellers
}

\author{
Sotirios Nik. Longinos ${ }^{1}$ (D) $\cdot$ Mahmut Parlaktuna $^{1}$
}

Received: 14 January 2021 / Accepted: 9 March 2021 / Published online: 20 March 2021

(c) The Author(s) 2021

\begin{abstract}
Hydrate formation characteristics and hydrodynamic behavior have been investigated for mixture of methane-propane hydrate formation with pure water and with the amino acid of lysine $1.5 \mathrm{wt} \%$ at 24.5 bars and $2{ }^{\circ} \mathrm{C}$. There were total 12 experiments with full and no baffle estimating the induction time, rate of hydrate formation, hydrate productivity and power consumption. The outcomes showed that radial flow experiments with radial flow have better behavior compared to mixed flow ones due to better interaction between gas and liquid. Furthermore, lysine experiments formed hydrates more quickly compared to pure water experiments showing that lysine functions as promoter and not as inhibitor. RT experiments consume more energy compared to PBT ones, while induction time is always smaller in RT experiments compared to PBT ones.
\end{abstract}

Keywords Lysine $\cdot$ Natural gas hydrates $\cdot$ Rate of hydrate formation $\cdot$ Induction time

\section{Introduction}

Augmenting planetary demand for natural gas (NG), the cleanest burning fossil fuel, necessitates the evolvent of large-scale stationary storage systems for NG to cater to widespread applications. Gas hydrate is a hopeful candidate for large-scale storage of natural gas (NG) in a costeffective, extremely safe/nonexplosive and environmental friendly way. There is high storage capacity, about $170 \mathrm{v} / \mathrm{v}$ aided by the relative ease in gas recovery with minimal energy requirement (Song et al. 2015; Li et al. 2016; Chong et al. 2016). There are three distinct hydrate structures, on the basis of both type and number of cavities and the size of guest molecules. These are structure I (sI), structure II (sII) and structure H (sH) (Ripmeester et al. 1987; Sum et al. 1997; Mao et al. 2002). Although hydrate formation processes can be regarded in many applications like energy storage materials, airconditioning systems and water desalination (Sloan and Koh 2008; Sun et al. 2011; Azizi et al. 2020; Ganat et al. 2019; Kelland 2011; Kelland et al. 2012), they are leading cause of pipeline blockage in upstream and midstream industry. As consequence different chemicals

Sotirios Nik. Longinos

sotirios.longinos@metu.edu.tr; s.n.longinos@gmail.com

1 Department of Petroleum and Natural Gas Engineering, Middle East Technical University, Ankara, Turkey inhibitors have been studied on the rate of hydrate formation by many research groups (Azizi et al. 2020; Ganat et al. 2019;Kelland 2011; Kelland et al. 2012; Niang et al. 2010; Valberg 2006). One solution to overcome blockage problem is the injection of hydrate inhibitors. There are thermodynamic kinetic inhibitors (THIs) and low dosage inhibitors which are divided to kinetic hydrate inhibitors (KHIs) and anti-agglomerates (AAs) (Sa et al. 2011). In this work, lysine as amino acid will be examined in specific composition if it functions as promoters or inhibitor with the three different impellers and the use or no of full baffle (FB). Until now, impellers examination (hydrodynamic behavior) had been used for different applications (Ghasemi et al. 2020,2021; Darjani et al. 2019; Mozaffaria et al. 2017) apart from gas hydrate formation.

\section{Experimental process}

A CSTR of internal volume of 1.561 has been designed and built to carry out studies on the scale up of gas hydrate formation. A schematic diagram of it is shown in Fig. 1. Hydrates in fact are formed in the reactor by injecting methane (95\%)-propane (5\%) (mixture) in the reactor, while there is already water and start rotating the shaft in specific values of temperature and pressure $\left(P=24.5\right.$ bars, $\left.\mathrm{T}=2{ }^{\circ} \mathrm{C}\right)$. It consists of polymethyl methacrylate (PMMA) the main 


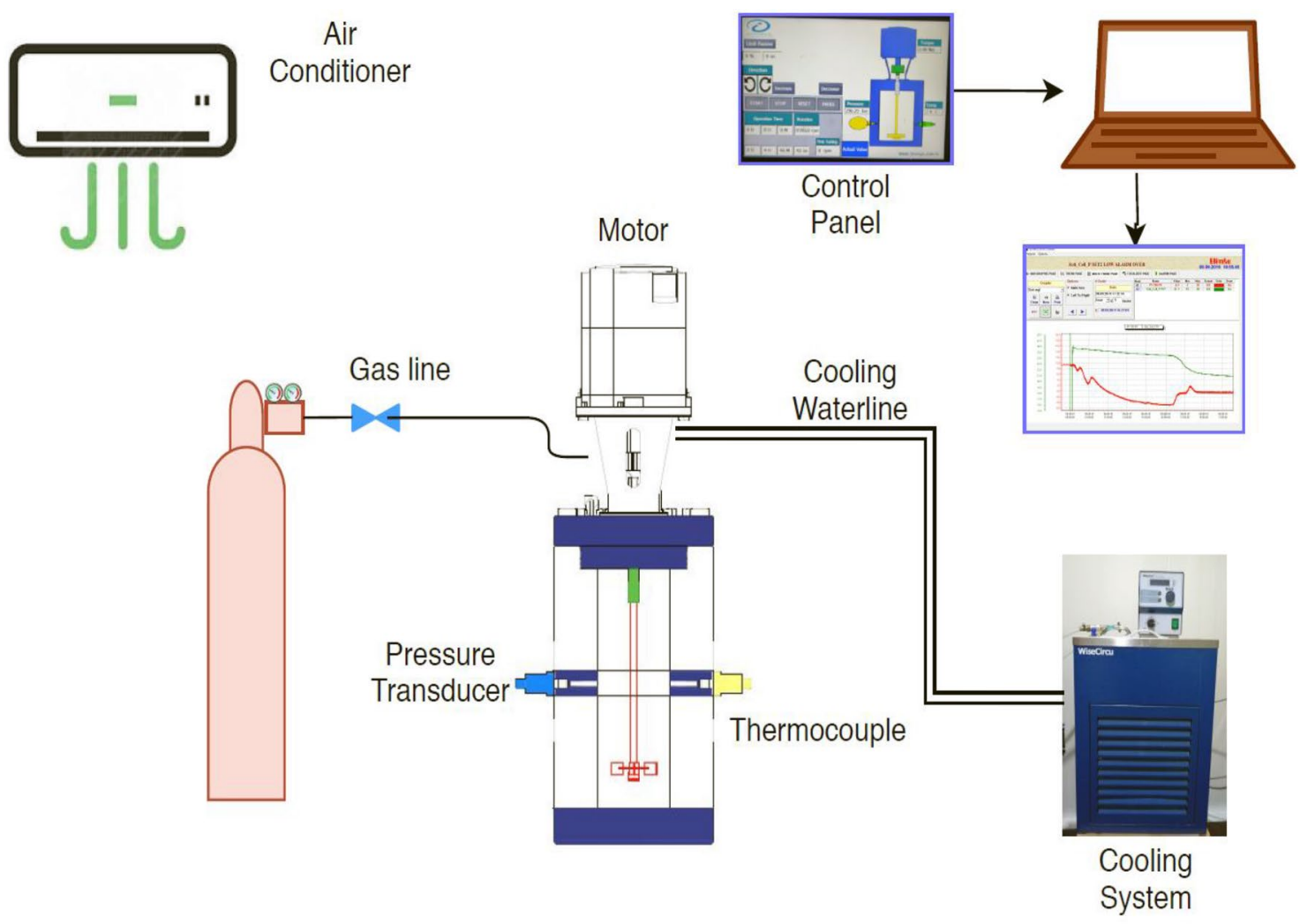

Fig. 1 Flowchart of experimental procedure of transparent reactor with RT

body with 2 steel (AISI 316L) outer circular disks which are mounted in the main body of the reactor where there are 4 inlets for the pressure transducer and thermocouple (in one of these 2 and more specifically in the first of the main body as you see it from down to up) and the other 2 circular disks in the upper operating for the servo motor receptacle and in the bottom acting as the base of the reactor. All discs are mounted with 8 steel studs, hence to function as a reactor main body. The polymethyl methacrylate vessel has an internal diameter of $80 \mathrm{~mm}$ and an internal length of $300 \mathrm{~mm}$. It has been designed for pressure values up to 30 bars and provided with a safety valve. In order to avoid friction heat due to rotational speed of impellers, cooling water is circulated around the shaft of the motor. The flow rate of refrigerated cooling bath (WCL-P12) is $12 \mathrm{~L} / \mathrm{min}$. The cooling medium is distillated water.

The temperature of the Refrigerated Cooling Bath was measured by a thermocouple inside of the bath. Two AISI $316 \mathrm{~L}$ stainless steel flanges are used to seal the reactor. One flange has appropriate ports for access to the interior. The seven ports ( 3 on flange and 4 on the body of the reactor) are used for supplying gas and measuring temperature and pressure. The temperature sensors are mineral insulated type TW/T (Threaded Type Thermowells) with accuracy $( \pm 0.2 \%)$ and measure the temperature inside in the middle part of the vessel. The Piezoresistive pressure sensors (Keller Seriers $21 \mathrm{Y}$ ) give digital output with accuracy $\pm 0.25 \mathrm{FS} \%$. The gas inlet line is equipped with a gas pressure regulator with accuracy 0.6. Gas is supplied by gas bottles through a pressure-reducing valve that provides adjustment of the pressure to the gas injection line. Voltage signals from pressure transducers and temperature sensors collected by a PLC unit (software) for data acquisition on a personal computer. The shaft and baffle are made by steel AISI 316L and AISI 304 equivalently, while the impellers are made by acrylolonitrile butadiene styrene (ABS) plastic. For the rotation is used servomotor type of High Inertia (permanent-magnet synchronous motor siemens model SIMOTICS S-1FL6. Figure 1 shows the flowchart of our experiments.

The gas mixture (methane $95 \%$ and propane $5 \%$ ) is injected through steel tube in the reactor, which is already found the distillated water. The volume of water is 0.41 (height of liquid is the same with the diameter of reactor, $8 \mathrm{~cm}$ ). The room temperature is $10^{\circ} \mathrm{C}$ and after feeding with the gas, we put the room temperature to $-5{ }^{\circ} \mathrm{C}$ until the temperature of our reactor reaches the $2{ }^{\circ} \mathrm{C}$. The rotation process starts when the temperature is $2{ }^{\circ} \mathrm{C}$ and the pressure is 24.5 bars, while we also decrease the temperature of the cold room from -5 to $0{ }^{\circ} \mathrm{C}$ (there is increase in temperature to $0{ }^{\circ} \mathrm{C}$ because we do not want 
the temperature to go less than $2{ }^{\circ} \mathrm{C}$ because hydrate will start form without rotation). The rotational period and our measurements are taken for a period of $3 \mathrm{~h}$ after the induction time (first nuclei of gas hydrates).

The main objective of this study is to investigate the effect of lysine and different impellers with full baffle (FB) and no baffle (NB) configurations on hydrate formation kinetics. Therefore, a tool must be devised to extract the kinetic data from raw experimental data. Application of real gas law $(\mathrm{PV}=\mathrm{znRT})$ for each data point with known pressure, temperature and free gas volume gives the change in number of moles of free gas with time. The gas compressibility factor of the real gas law $\mathrm{Z}$ is estimated by using Lee and Kesler's (1975) compressibility factor expression (Longinos and Parlaktuna2021a). A sample plot of change in free gas number of moles is given in Fig. 2 for $\mathrm{CH}_{4}-\mathrm{C}_{3} \mathrm{H}_{8}$-SI-PBTU-FB-Lysine $1.5 \mathrm{wt} \%$.

Figure 3 is plotted with the same data of Fig. 2 but covering only hydrate formation period. A third-order polynomial fit of experimental data result with Eq. 1.

$n=-4.74 \times 10^{-16} t^{3}+1.44 \times 10^{-11} t^{2}-1.48 \times 10^{-7} t+3.89 \times 10^{-3}$

where: $n=$ Number of moles of free gas, mol and $t=$ Time, $\mathrm{s}$

The derivative of Eq. 1 results with the gas consumption rate (Eq. 2) which can be considered as the hydrate formation rate. $\frac{\mathrm{d} n}{\mathrm{~d} t}=-3 \times 4.74 \times 10^{-16} t^{2}+2 \times 1.44 \times 10^{-11} t-1.48 \times 10^{-7}$

where $\frac{\mathrm{d} n}{\mathrm{~d} t}=$ Gas consumption rate, mol/s and $t=$ Time, $\mathrm{s}$

Comparison of gas consumption rates of different experiments will be done by utilizing gas consumption rate equations (Eq. 2 is an example) with four different time values, namely 1, 600, 1200 and $1800 \mathrm{~s}$. Table 1 presents the gas consumption rates of experiment $\mathrm{CH}_{4}-\mathrm{C}_{3} \mathrm{H}_{8}$-SI-PBTU-FB-Lysine, as an example.

Power consumption was calculated based on the torque measured every second based on the following equation:

$P_{c}=T_{q} \times 2 \pi N$

where $T_{q}$ is the Torque in N-m and $\mathrm{N}$ is the rotational speed in rps, and power consumption is in Watt.

The power consumption at every second over the duration of hydrate formation for each experiment was summed to obtain overall power consumption during the experiment. The duration for the calculation of overall power consumption is the sum of the induction time of a given experiment and the hydrate formation duration of the experiment with shortest duration.

Hydrate productivity is defined by the formula

$N R_{30}=\frac{R_{30}}{V_{\text {water }}}\left(\mathrm{mol} \times l^{-1} \times s^{-1}\right)$

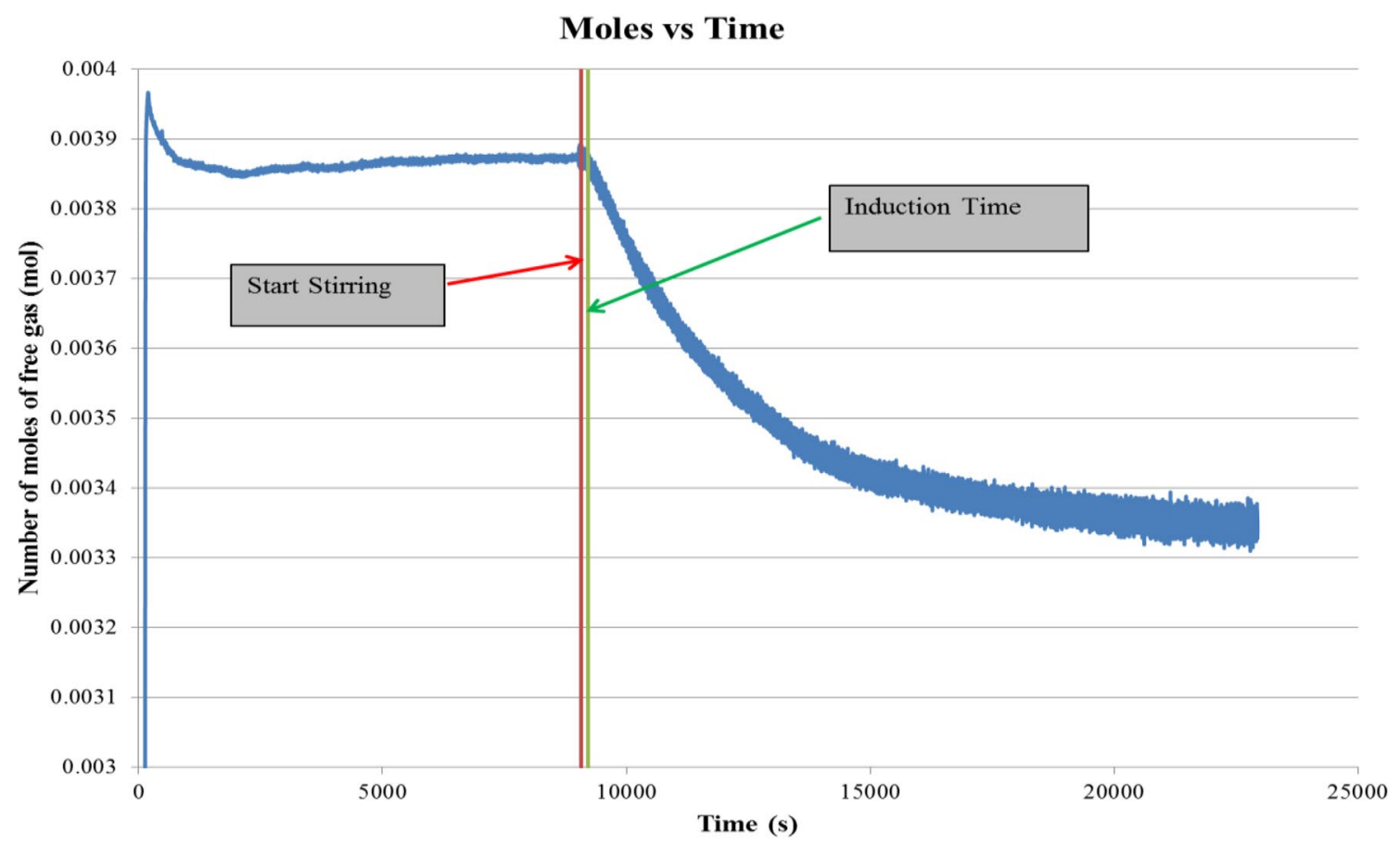

Fig. 2 Change in number of moles of free gas in $\mathrm{CH}_{4}-\mathrm{C}_{3} \mathrm{H}_{8}$-SI-PBTU-FB-Lysine experiment 
where $V_{\text {water }}$ is the volume of water (1) in the reactor,

$R_{30}$ is the rate of hydrate growth $\left(\mathrm{mol} \times \mathrm{s}^{1}{ }^{1}\right)$ calculated by fitting the gas uptake due to hydrate growth versus time for the first $30 \mathrm{~min}$ after the induction time.

\section{Results and discussions}

Table 2 summarizes the outcomes of single impeller such as PBTU, PBTD and RT, methane (95\%)-propane $(5 \%)$ mixture experiments with pure water and the amino acid of lysine in $1.5 \%$ wt. In all RT experiments, hydrate formation almost started immediately compared to PBTU and PBTD ones. Furthermore, the highest value of induction time belonged to pure water compared to lysine experiments.
Fig. 3 Gas consumption rate equation for lysine

\section{CH4-C3H8-RT-NB-SI-LYSINE}

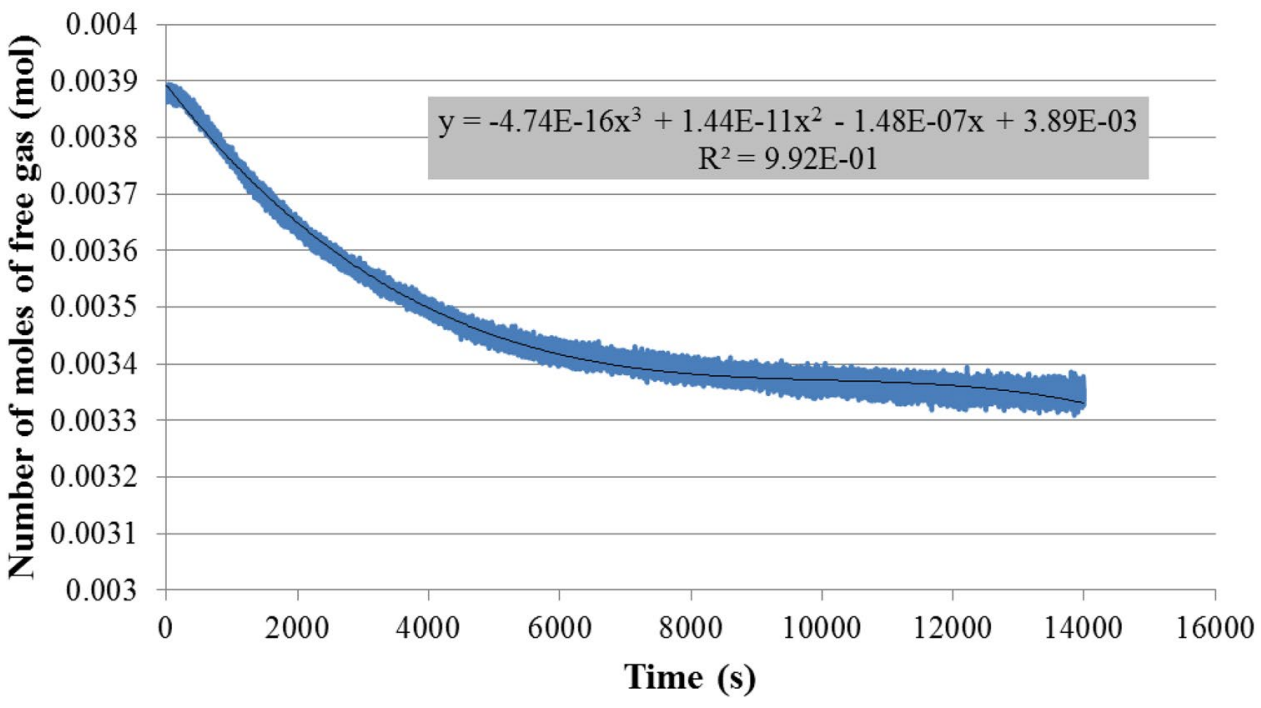

Table 1 Gas consumption rates of experiment $\mathrm{CH}_{4}-\mathrm{C}_{3} \mathrm{H}_{8}$-SIRT-NB-Lysine

\begin{tabular}{lllll}
\hline Time $(\mathrm{s})$ & 1 & 600 & 1200 & 1800 \\
\hline Gas consumption rate $(\mathrm{mol} / \mathrm{s})$ & $-1.48 \times 10-^{7}$ & $-1.31 \times 10-^{7}$ & $-1.15 \times 10-^{7}$ & $-1.01 \times 10^{-7}$ \\
\hline
\end{tabular}

Table 2 Summary of outcomes of single impeller with pure water and different amino acids experiments (*where SE is standard deviation and $n=2$ the number of experiments, while the results are for 1 and $600 \mathrm{~s}$ )

\begin{tabular}{|c|c|c|c|c|c|c|}
\hline System & $P_{\text {exp }}$ (bars) & $\mathrm{T}\left({ }^{\circ} \mathrm{C}\right)$ & Induction Time (s or min) & $\begin{array}{l}\text { Hydrate productiv- } \\
\text { ity }\left(10^{-8} \mathrm{~mol} / \mathrm{s} \times 1\right)\end{array}$ & $\begin{array}{l}\left(\mathrm{R}^{2}\right) \text { in Rate of } \\
\text { Hydrate formation } \\
\text { graphs }\end{array}$ & $\begin{array}{l}\text { Standard Error } \\
* \mathrm{SEX}=\mathrm{SE} / \mathrm{n}^{1 / 2}\end{array}$ \\
\hline PBTU-FB-Water & 24.5 & 2 & $42 \mathrm{~min}$ & 24.5 & 0.976 & $1.44 / 1.31$ \\
\hline PBTU-FB-Lysine-1.5\% wt & 24.5 & 2 & $1 \mathrm{~min}$ and $14 \mathrm{~s}$ & 20.8 & 0.996 & $1.86 / 1.31$ \\
\hline PBTD-FB-Water & 24.5 & 2 & $46 \min$ & 22.7 & 0.984 & $1.27 / 1.22$ \\
\hline PBTD-FB-Lysine-1.5\% wt & 24.5 & 2 & $2 \mathrm{~min}$ & 24.7 & 0.997 & $1.54 / 1.37$ \\
\hline RT-FB-Water & 24.5 & 2 & $2 \mathrm{~min}$ & 26.0 & 0.982 & $1.61 / 1.50$ \\
\hline RT- FB-Lysine-1.5\% wt & 24.5 & 2 & $1 \mathrm{~min}$ & 24.7 & 0.997 & $1.48 / 1.28$ \\
\hline PBTU-NB-Water & 24.5 & 2 & $16 \min$ & 18.8 & 0.987 & $1.72 / 1.55$ \\
\hline PBTU-NB-Lysine- $1.5 \% \mathrm{wt}$ & 24.5 & 2 & $3 \min$ & 21.5 & 0.979 & $1.34 / 1.25$ \\
\hline PBTD-NB-Water & 24.5 & 2 & $14 \min$ & 23.2 & 0.981 & $1.58 / 1.39$ \\
\hline PBTD-NB-Lysine-1.5\% wt & 24.5 & 2 & $4 \min$ & 21.3 & 0.988 & $1.69 / 1.44$ \\
\hline RT-NB-Water & 24.5 & 2 & $3 \mathrm{~min}$ & 25.8 & 0.986 & $1.73 / 1.54$ \\
\hline RT- NB-Lysine- $1.5 \%$ wt & 24.5 & 2 & $2 \min$ & 25.3 & 0.992 & $1.42 / 1.12$ \\
\hline
\end{tabular}


It should be mentioned that from perspective of induction time all different impeller experiments with lysine behaved as promoters and not as inhibitors with the objection that hydrate formation is a stochastic process (although that in our experiments that were used for duplicate our results, induction times were similar and did not show different outcomes). Column 5 shows the hydrate productivity. The highest value of hydrate productivity takes place both in full and no baffle experiments is RT with pure water experiment ( $26 \mathrm{~mol} / \mathrm{s} \times 1$ and $25.8 \mathrm{~mol} / \mathrm{s} \times 1$ ). On the other hand, the lowest values of hydrate productivity takes place in pitched blade turbine upward trending (PBTU) with lysine for full baffle (FB) experiments with value $20.8 \mathrm{~mol} / \mathrm{s} \times 1$, while in no baffle (NB) experiments the lowest value of hydrate productivity takes place in PBTU with pure water experiment with value $18.8 \mathrm{~mol} \times / \mathrm{s}$. Hydrate productivity outcomes follow the same row like rate of hydrate formation in first second showing that the process of hydrate formation increases almost analogically through period of time.

The baffles provide axial flow and eliminate the central vortex in a stirred tank. When full baffles are used, it is expected to observe the axial motion of the reactor contents beginning from the bottom of the tank. On the other hand, central vortex could be useful in incorporating gas if the vortex reaches the impeller; however, excessive entrance of the gas would have a significant effect on the hydrodynamics in the tank and the gas entrance through the vortex can become an undesired situation. Based on these, it is seen here that when full baffles are used, there is sufficient gas entrance to the system and the axial flow provided by the baffles allows for the induction to begin much faster. Furthermore, in all experiments, an increase in the temperature of the system is observed with the initiation of hydrate since the reaction is exothermic. Table 2 and pre-last shows that rate of hydrate formation fits with third-order polynomial fit very well since all $\mathrm{R}^{2}$ are above 0.975 .

The change in the number of moles of free gas after the initiation of hydrate formation was used to calculate the rate of hydrate formation at four different times $(1 \mathrm{~s}, 10,20$ and $30 \mathrm{~min}$ ). Figures 4 and 5 present the hydrate formation rates of PBTU, PBTD and RT impeller experiments with pure water and lysine $1.5 \% \mathrm{wt}$, respectively.

From hydrodynamic perspective in Fig. 4, it is observed that in experiments with mixed flow (PBTU and PBTD), the full baffle experiments have higher values compared to radial flow experiment. On the other hand, in radial flow experiment, the experiment with no baffle has higher value of rate of hydrate formation compared to full baffle experiment. Among all experiments of water, radial flow experiment with no baffle has the highest value of hydrate formation rate $\left(14.6 \times 10-{ }^{8} \mathrm{~mol} / \mathrm{s}\right)$. The same behavior occurs also in the experiments with lysine mixed flow experiments with full baffle which have higher values of rate of hydrate formation compared to no baffle, while the opposite occurs

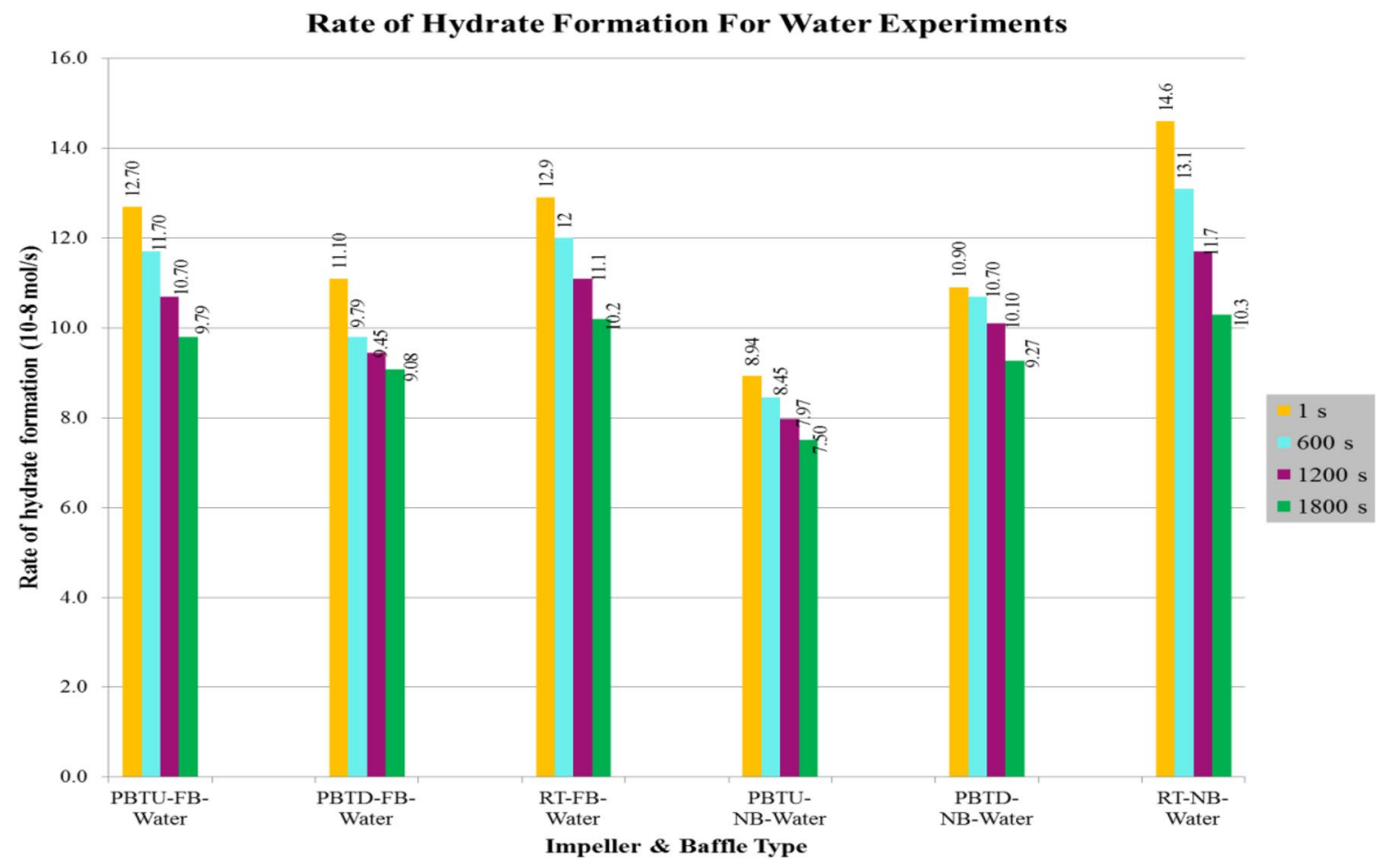

Fig. 4 Rate of hydrate formation for water experiments 


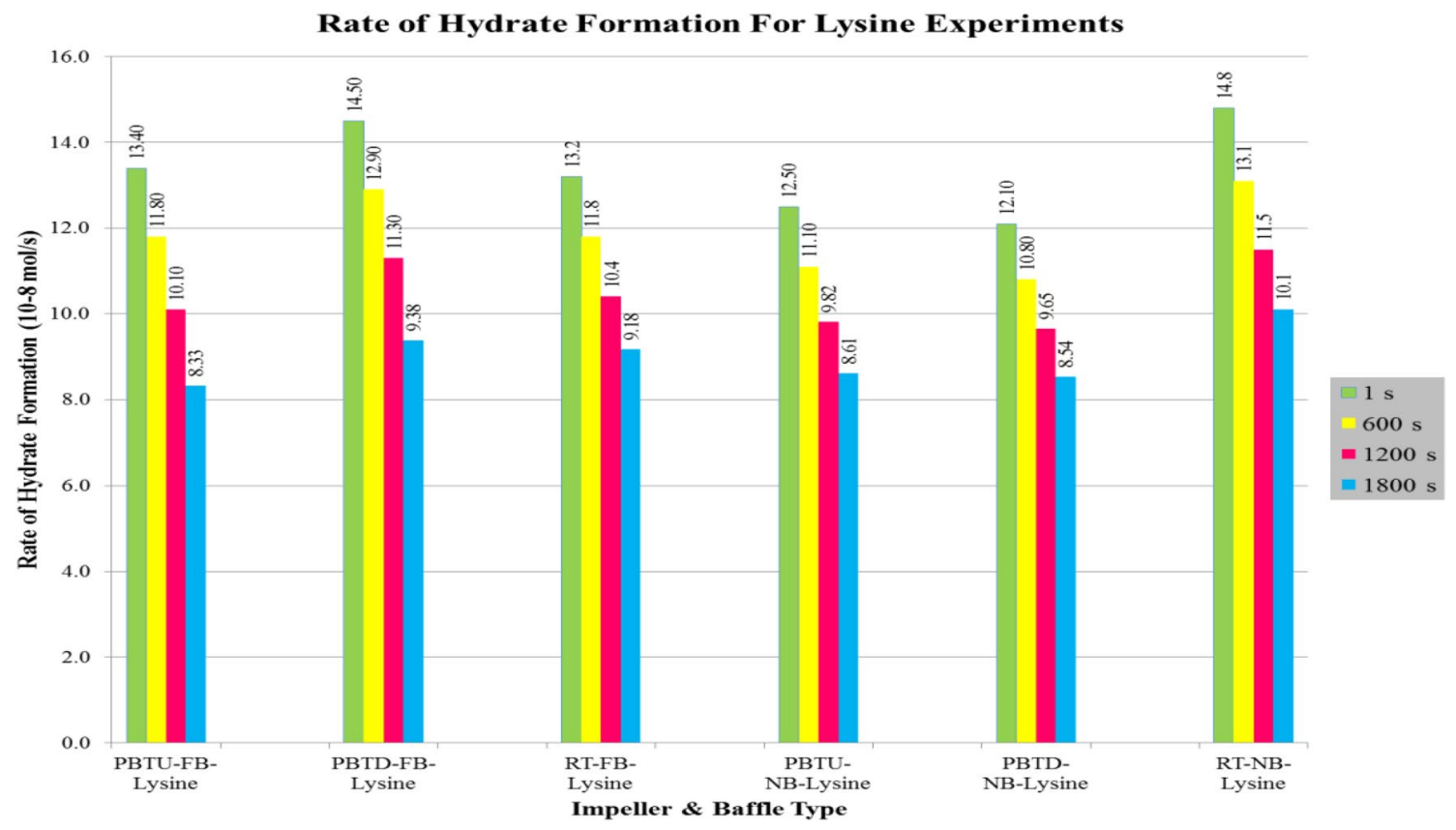

Fig. 5 Rate of hydrate formation for lysine experiments

in radial flow experiment. The highest value of rate of hydrate formation among all lysine experiments occurs in experiment with no baffle (NB) and radial flow with value $\left(14.8 \times 10-{ }^{8} \mathrm{~mol} / \mathrm{s}\right)$. As an outcome, it is observed that the central vortex in a stirred tank with radial flow works positively compared to mixed flow which works negatively. From Figs. 4 and 5, it is noticed that all experiments with lysine have higher values of hydrate formation compared to pure water showing us that lysine works as promoter no matter the flow (radial or mixed) or the design inside the reactor (full or no baffle). Among all the experiments with no baffle, the highest value of rate of hydrate formation occurs in RT with lysine experiment $\left(14.8 \times 10-^{8} \mathrm{~mol} / \mathrm{s}\right)$ while in experiments with full baffle the highest value of rate of hydrate formation takes place in PBTD with lysine experiment $\left(14.5 \times 10-{ }^{8} \mathrm{~mol} / \mathrm{s}\right)$. This shows that radial flow with full or no baffle experiment presents a conduct which indicates a better level of gas-liquid contact by giving the permission to mass transfer impedances to be appreciably diminished which eventually guided at beneficial mixing intensity. Better pumping capacity, uniform shear field and good contact ability can be suspected to be the reason of this outcome which comes into accordance with previous results in larger scale (Longinos and Parlaktuna2021a,b ,c,2020; Douieb et al. 2015). Moreover, although lysine as charged side chain group, it forms a van der Waals interaction or electrostatic interactions with crystal surface which generally delay nucleation and confound more growth of the hydrate crystals (Kyte and Doolittle 1982), the dynamic, however, of this reaction does not allow any delay cancel the function of lysine as a catalyst (promoter).

Last parameter that is estimated is the power consumption of all 12 experiments by the use of PBTU, PBTD and RT impeller. The outcomes are presented in Figs. 6, 7 and 8 for PBTU, PBTD and RT experiments, respectively.

In both experiments with mixed flow (PBTU and PBTD) is observed that the experiment with pure water has higher value of power consumption compared to other ones. This takes place due to long period that there is between start stirring and induction time in pure water experiments whiles in lysine experiments is only few minutes. In second position in both mixed flow experiments come the experiment with $1.5 \%$ wt of lysine. Furthermore, in mixed flow experiments with full baffle higher values have the experiments with pure water while in no baffle experiments higher values of power consumption have the lysine experiments. Among the two groups of mixed flow impeller experiments, PBTD experiments have higher values of power consumption in all relatively experiments with the exception of full baffle with pure water experiment which is also confirmed by literature (Longinos and Parlaktuna2021c,2020; Douieb et al. 2015).

In RT experiments where the period of total process is almost the same, it is observed the opposite conduct compared to mixed flow experiments (PBTU and PBTD). In full baffle experiments, the highest value of power consumption took place in lysine experiment, while in no baffle 
Fig. 6 Power consumption of PBTU impeller experiments

\section{Power consumption for PBTU impellers}

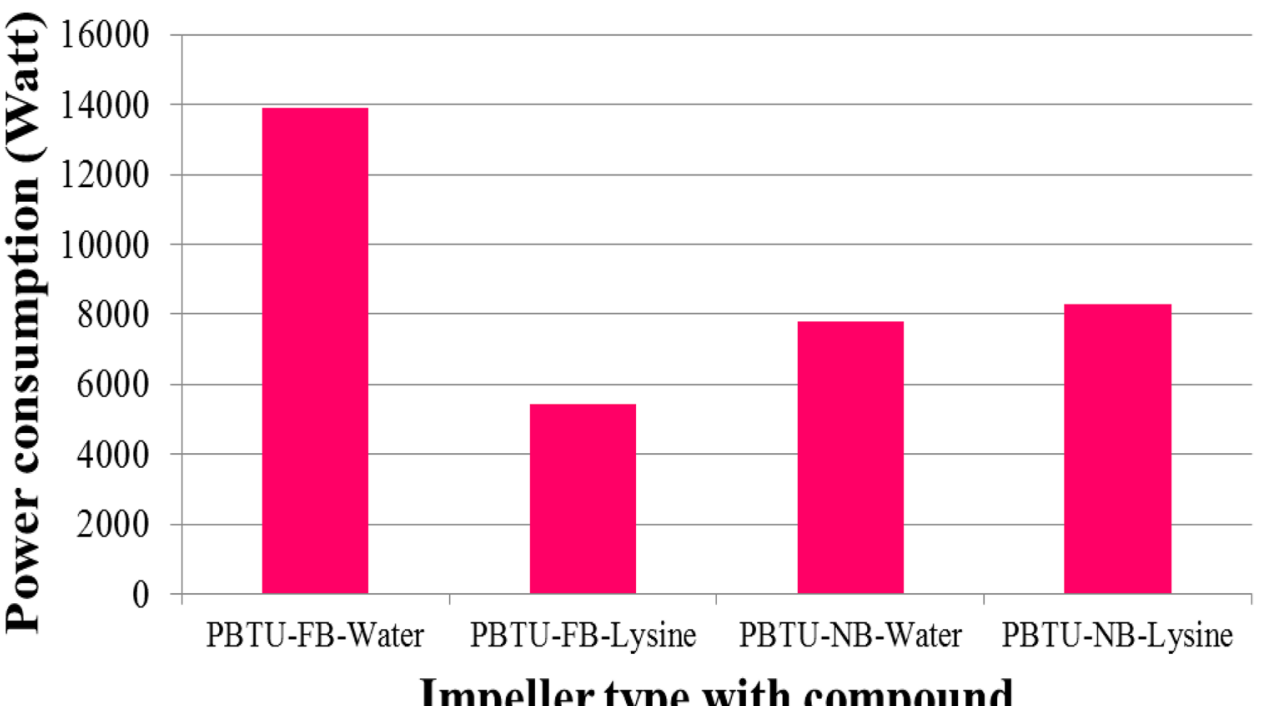

Fig. 7 Power consumption of PBTD impeller experiments

\section{Power consumption for PBTD impellers}

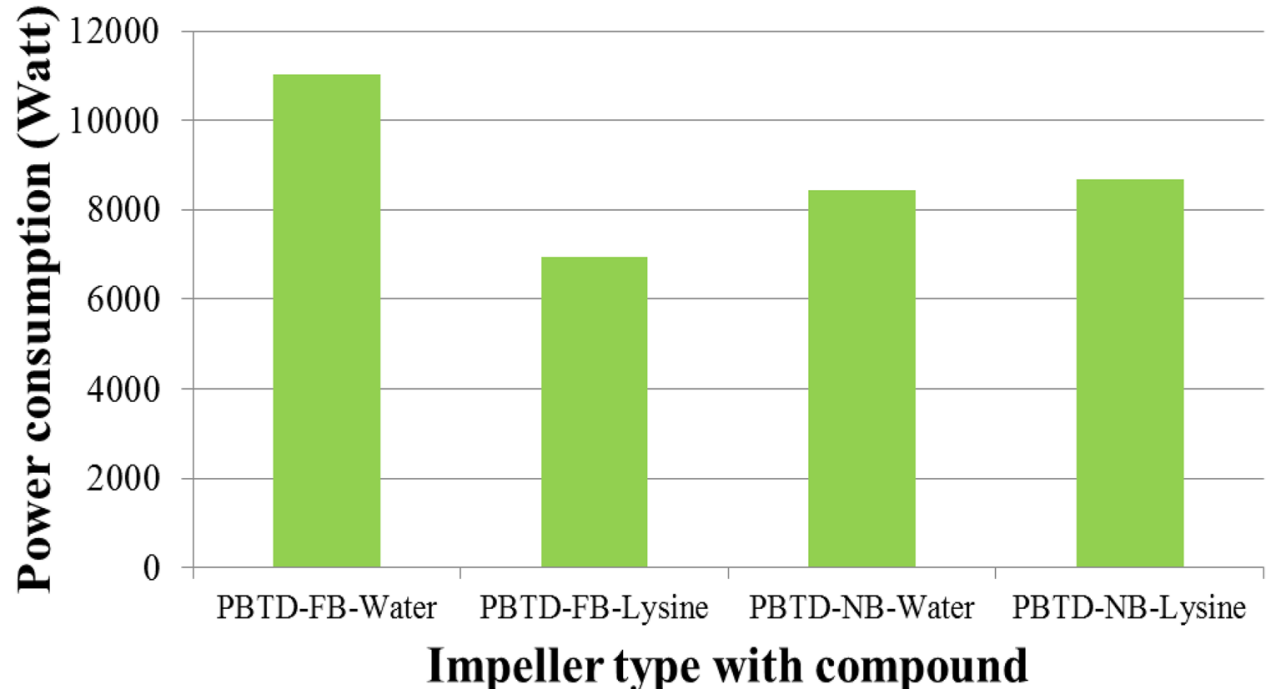

experiments the highest value of power consumption took place in pure water. As general observation RT experiments consume more energy (average value is always higher) compared to PBT experiments in case they work for same time with the exception of full baffle water experiments (Longinos and Parlaktuna2021a,c).

\section{Conclusion}

In this research work, there was an investigation of lysine and its function as promoter or inhibitor in the process of mixture hydrate formation parallel with the examination of three different flows. The outcomes of the experiments show that all different experiments with lysine $1.5 \% \mathrm{wt}$ behave as promoter. The highest rate of hydrate formation of methane (95\%)-propane $(5 \%)$ gas hydrate took place in radial flow, showing that radial flow creates a better level of gas-liquid contact. The induction time of radial flow experiments is smaller compared to mixed flow ones. Hydrate productivity values follow the same row like rate of hydrate formation. Mixed flow experiments with full baffle and water consume more energy compared to other experiments due to the fact that they have long period from start stirring until hydrate formation. 
Fig. 8 Power consumption of RT impeller experiments

\section{Power consumption for RT impellers}

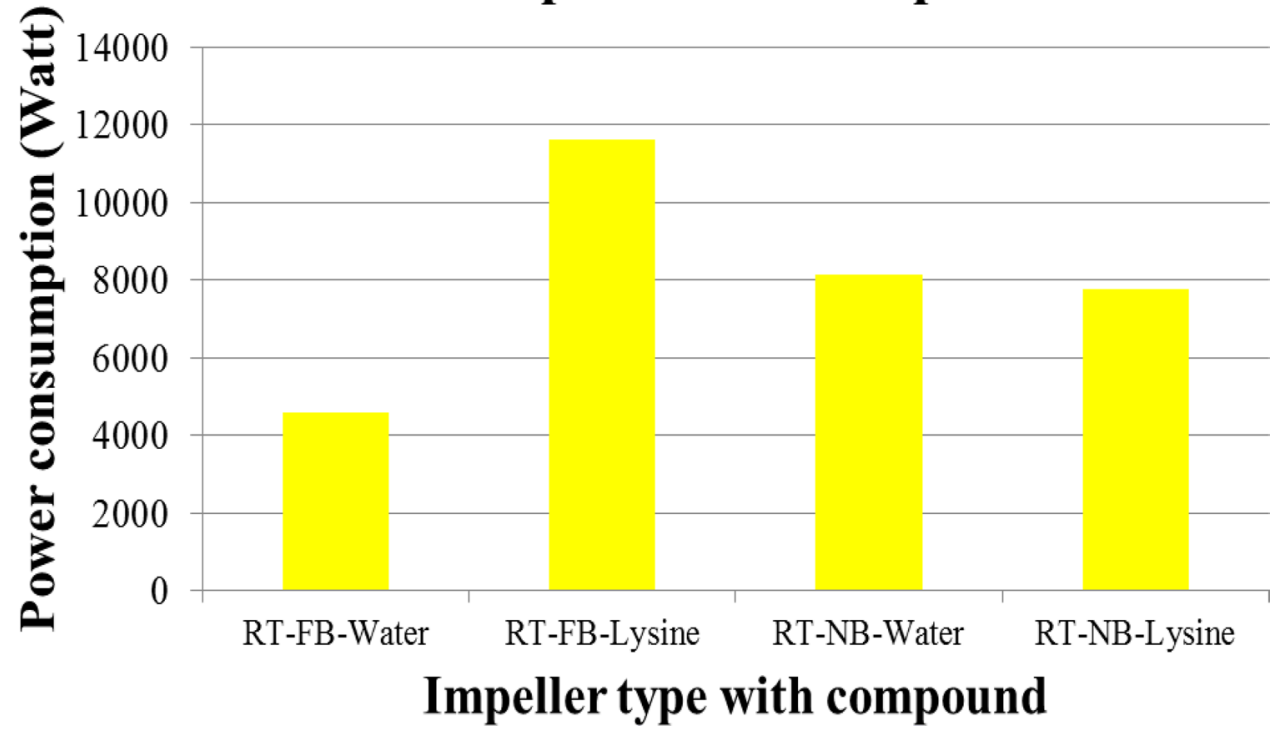

Supplementary Information The online version contains supplementary material available at https://doi.org/10.1007/s13202-021-01146-w. Acknowledgements The financial support from TUBITAK (project:
117M158) is greatly appreciated

Funding The paper was written behalf of phd thesis of Dr Sotirios Longinos under the project with title: Design and Kinetic Analysis of a Stirred Tank Reactor For Natural Gas Hydrate Formation with number: $117 \mathrm{M} 158$ and it was funded by TUBITAK.

\section{Declaration}

Conflict of interest The authors declare that they have no known competing financial interests or personal relationships that could have appeared to influence the work reported in this paper.

Open Access This article is licensed under a Creative Commons Attribution 4.0 International License, which permits use, sharing, adaptation, distribution and reproduction in any medium or format, as long as you give appropriate credit to the original author(s) and the source, provide a link to the Creative Commons licence, and indicate if changes were made. The images or other third party material in this article are included in the article's Creative Commons licence, unless indicated otherwise in a credit line to the material. If material is not included in the article's Creative Commons licence and your intended use is not permitted by statutory regulation or exceeds the permitted use, you will need to obtain permission directly from the copyright holder. To view a copy of this licence, visit http://creativecommons.org/licenses/by/4.0/.

\section{References}

Azizi A, Johns ML, Aman ZM, May EF, Ling NA, Husin H (2020) EfFect of hydrate anti-agglomerants on water-in-crude oil emulsion stability. J Pet Explor Prod Technol 10:139-148. https://doi. org/10.1007/s13202-019-0691-0
Chong ZR, Yang SHB, Babu P, Linga P, Li X-S (2016) Review of natural gas hydrates as an energy resource: prospects and challenges. Appl Energy 162:1633-1652

Darjani S, Koplik J, Banerjee S, Pauchard V (2019) Liquid-hexaticsolid phase transition of a hard-core lattice gas with third neighbour exclusion. J Chem Phys 151:104702. https://doi.org/10. $1063 / 1.5123231$

Douieb S, Fradette L, Bertrand F, Haunt B (2015) Impact of the fluid flow conditions on the formation rate of carbon dioxide hydrates in as semi-batch stirred tank reactor. AIChE 61(12):4387-4401

Ganat T, Hrairi M, Regassa S (2019) Experimental investigation of gas-oil-water phase flow in vertical pipes: influence of gas injection on the total pressure gradient. J Pet Explor Prod Technol 9:3071-3078. https://doi.org/10.1007/s13202-019-0703-0

Ghasemi H, Darjani S, Mazloomi H, Mozaffari S (2020) Preparation of stable multiple emulsions using food-grade emulsifiers: evaluating the effects of emulsifier concentration, W/O phase ratio, and emulsification process. SN Appl Sci 2:2002. https://doi.org/10. 1007/s42452-020-03879-5

Ghasemi H, Mozaffari S, Mousavi SH, Aghabarari B, Abu-Zahra N (2021) Decolorization of wastewater by heterogeneous fenton reaction using $\mathrm{MnO} 2-\mathrm{Fe} 3 \mathrm{O} 4 / \mathrm{CuO}$ hybrid catalysts. J Environ Chem Eng 9:105091. https://doi.org/10.1016/j.jece.2021.105091

Kelland MA (2011) A review of kinetic hydrate inhibitors: tailormade warer-soluble polymers for oil and gas industry applications. Advances in materials science research. Nova Science Publishers Inc., New York

Kelland MA, Kvaestad AH, Astad EL (2012) Tetrahydrofuran hydrate crystal growth inhibition by trialkylamine oxides and synergism with the gas kinetic hydrate inhibitor poly ( $\mathrm{N}$-vinyl caprolactam). Energy fuel 26:4454-4464

Kyte J, Doolittle RF (1982) A simple method for displaying the hydropathic character of a protein. J Mol Biol 157:230-235

Lee BI, Kesler MG (1975) A generalized thermodynamic correlation based on three Parameter corresponding states. AIChE 21:510-527

Li X-S, Xu C-G, Zhang Y, Ruan X-K, Li G, Wang Y (2016) Investigation into gas production from natural gas hydrate: a review. Appl Energy 172:286-322 
Longinos SN, Parlaktuna M (2020) The effect of experimental conditions on methane (95\%)-propane (5\%) hydrate formation. Energies 13(24):6710. https://doi.org/10.3390/en13246710

Longinos SN, Parlaktuna M (2021) Kinetic analysis of methanepropane hydrate formation by the use of different impellers. ASC Omega 6:1636-1646. https://doi.org/10.1021/acsomega. 0c05615

LonginosParlaktuna SNM ( 2021b) The Effect of experimental conditions on methane hydrate formation by the use of single and dual impellers. React Kinet Mech Catal 132(2):1-24. https://doi.org/ 10.1007/s11144-021-01937-6

LonginosParlaktuna SNM (2021a) Kinetic analysis of dual impellers on methane hydrate formation. Int J Chem React Eng 19(2):155-165. https://doi.org/10.1515/ijcre-2020-0231

Mao WL, Goncharov AF, Struzhkin VV, Guo Q, Hu J, Shu J, Hemley RJ, Somayazulu M, Zhao Y (2002) Hydrogen clusters in clathrate hydrate. Science 297:2247-2249

Mozaffaria S, Tchoukova P, Mozaffaric A, Atiasd J, Czarneckia J, Nazemifarda N (2017) Capillary driven flow in nano channelsapplication to heavy oil rheology studies, Colloids and Surfaces A: physicochem. Eng Asp 513:178-187. https://doi.org/10.1016/j. colsurfa.2016.10.038

Niang F, Zhang L, Tu Y, Jiang G, Shi M (2010) Gas hydrate formation, agglomeration and inhibition in oil-based drilling fluids for deepwater drilling. J Nat Gas Chem 19:234-240
Ripmeester JA, Tse JS, Ratcliffe CI, Powell BM (1987) A new clathratehydrate structure. Nature 325:135-136

Sa JH, Lee BR, Park DH, Han K, Chun DH, Lee KH (2011) Amino acids are natural inhibitors for hydrate formation in $\mathrm{CO}_{2}$ formation. Sci Rep 3:1-7

Sloan EDD, Koh CA (2008) Clathrate hydrates of natural gases, 3rd edn. CRC Press, Taylor and Francis Group, Boca Raton

Song Y, Cheng C, Zhao J, Zhu Z, Liu W, Yang M et al (2015) Evaluation of gas production from methane hydrates using depressurization, thermal stimulation and combined methods. Appl Energy 145:265-277

Sum AK, Burruss RC, Sloan ED (1997) Measurement of clathrate hydrates via Raman spectroscopy. J Phys Chem B 101:7371-7377

Sun C, Li W, Yang X, Li F, Yuan Q, Mu L, Chen J, Liu B, Chen G (2011) Progress in research of of gas hydrate. Chin J Chem Eng 19:151-162

Valberg T (2006) Efficiency of Thermodynamic Inhibitors for Melting Gas Hydrates (Master Thesis of NTNU)

Publisher's Note Springer Nature remains neutral with regard to jurisdictional claims in published maps and institutional affiliations. 